\title{
Your feet are not your feet
}

\section{(Rephrased from Children by Kahlil Gibran)}

\author{
By Jenni-Juulia Wallinheimo-Heimonen \\ textile and conceptual artist
}

I was seven years old when I saw a stump for the first time. My hoarsely laughing grandma wrote film subtitles for a living, and smoked so much tobacco that her leg had to be amputated. I thought she needed a prosthesis. But the stump was bruised, inflamed, and so sore that the prosthesis could not even be considered. I overheard adults discussing a traditional method of using leeches to treat the wound. The following night I had a nightmare where Grandma was dangling her feet in a lake full of blood-thirsty beasts.

In the 1980s, prostheses were passive, skin-coloured mannequin pieces made of hard plastic. I stared at them in the nursing home where Grandma moved after the toes on her other foot were amputated. Later, in 2007, when I organized Finland's first assistive technology design competition, I started collecting pictures of assistive devices. I divided these into folders based on how the product reflected its designer's perception of disability: 1. fashionable/attractive ones; 2 . practical/functional ones; and 3. shameful/degrading aids. The prosthesis that I saw in my childhood would today be somewhere between practical and embarrassing, even though this type is still a luxury in most countries around the world.

\section{Technology embodies values}

Assistive devices utilise robotics, material- and nanotechnology, together with neuroprosthetics. The stump is not a dead end in the transmission of physiological data, but is intended to provide bidirectional communication between the prosthesis and the user. There are prosthetic hands that are capable of transmitting "skin-like" impulses to the brain. The neural interface makes it possible to send mental command signals to prosthesis servos via muscle electrodes. I'm super happy if "life-like" bionic body-parts help people after accidents and traumatic losses. However, as a third generation with a hereditary disability, I can't help but wonder when repairing an individual to bring them closer to an imaginary norm is good for disability policy-and when the trend is actually delaying the development of our human rights by reinforcing the outdated medical model of disability.

If a middle-aged, working, straight, white man with a family loses his leg, he is allowed to participate in the Paralympics, but he doesn't necessarily become disabled. In the 21 st century, disability is not an automatic consequence of 
a missing limb. Impairments become disabilities when social structures leave some people outside common experiences. Disability occurs when we treat people differently, and undesirably, because of their features. If a privileged person has a good safety net, and if he is regarded as almost the same after an injury, he does not instinctively recover from disability prejudices in rehabilitation. Nor does he heal from marginal allergy, ${ }^{1}$ and start writing songs about thresholds and segregation harms in special education. Still, he might do that - later.

The current model of disability excludes quite a lot of people who have first-hand experience of change, unravelling, or shrinkage of the body, but have not necessarily experienced-and hopefully never will experience-discrimination, otherness, poverty and violence. These experiences, however, are the reality for most people with inborn disabilities, in a life where social services cost estimates decorate our very first playsuits. If the world is set up for you since birth, and society doesn't kick you off the field after the traumatic loss of breast, organ, toe, finger or limb, you may still have a long way to go before you meet the definition of disability.

New, well-meaning professional groups have appeared alongside doctors, physiotherapists and prosthetists to fix and mend people with disabilities so that they resemble the majority. But rehabilitating and equipping people to what is supposedly normal isn't politically correct anymore for any minority other than us: persons with disabilities (PWDs). Instead of solutions that concentrate on individuals and imitate conventional bodies, we should actively develop practices to destroy societal obstacles that perpetuate discrimination. In the UN Convention on the Rights of Persons with Disabilities, persons with disabilities include those who have long-term physical, mental, intellectual or sensory impairments which in interaction with various barriers may hinder their full and effective participation in society on an equal basis with others. But how much knowledge of human rights policy can be required from the designers of prosthetics or cochlear implants?

\section{From emergency to empowerment}

In developed nations, prosthetics, and other assistive equipment whose design prioritises compensation, are old-fashioned right from the start. I claim that they even maintain the low status of disability. A practical but ugly aid is like the uniform of an unproductive outcast, that by default positions its user on the margins. Such prostheses are reality for the majority who cannot afford preferable options, or in whom society does not want to invest. In a way, prostheses are unique and custom built, but the elements supporting identity are not included in the package.

In Finland, assistive technology is mostly paid for by municipalities and hospital districts, or in some cases is covered by traffic or accident insurance. Sophie Oliveira de Barrata's sculptural prostheses for Victoria Modesta and other celebrities wouldn't win this public bidding process. Those devices are dreams that require wealth or exceptional artisanal skills to come true.

In autumn 2018, the Ministry of Social Affairs and Health published guidelines on national criteria for assigning assistive devices in medical rehabilitation. The purpose of the guide was to make instructions on assistive devices consistent throughout the country. In the past, there were major differences across Finland especially in providing expensive devices. When allocating prostheses, a person's activity level is evaluated. In practice, a woman over the age of fifty who exercises regularly will rarely receive as good a prosthesis as a man in his twenties with no particular sporting hobbies. Procurement has also been centralised among a handful of players to save money. People don't always receive the best assistive device for them, only the best device available from the chosen supplier.

I hope that rehabilitation engineering studies will attract more people with disabilities in the future. Subconscious fear, pity and prejudices hamper empathic design thinking, which is reflected in the products. As a hobby, I like to reveal the patronising guardianships and harmful approaches behind assistive innovations. Technical features are often valued more highly than visual appearance, 
even though prostheses, crutches and wheelchairs are parts of everyday self-image, along with clothing choices. Users are invited to participate only after the primary function of a new device has already been established; when it is, for example, decided to solve mobility difficulties with a prosthesis. The aim of product design for people with disabilities is almost never to find alternative ways of being human.

The most common form of discrimination faced by people with disabilities is an inaccessible environment. If you don't walk, you can't go everywhere. This discriminatory attitude is so pervasive in our culture that people often take it for granted, as correct, even neutral. A foot prosthesis expands the environment more than the coolest portable vehicle with Al gadgets. Yet many disability activists claim that the medicalised viewpoint overrates walking. Consequently, there are still children who have not been allowed to use a wheelchair, but are instead forced to walk for purposes of rehabilitation. The result is sad childhood memories of shambling alone behind the others, suffering from pain, and living in constant fear of falling over.

\section{New interpretations of assistive technology disrupt purity}

In 2011, I facilitated a workshop for landmine survivors in Bosnia Herzegovina with the topic "the assistive devices of your dreams". Participantswho were mostly former soldiers-indicated that the two most important features of a prosthesis are: getting women and making money. They wanted folding wheels for their foot prostheses so they could skateboard when in a hurry, and narrow displays on the surface to sell advertising space, since people already stared at their feet. These guys wanted to display blinking hearts as they pass a beautiful woman and campaign against the war. I got sick with prosthesis-envy for not having such versatile artificial body parts! Except, that is, for hearing aids that I can switch off when I need to concentrate.

In another workshop, a participant came up with the idea of a soft, allergy-free, purring pet hand-prosthesis, that would tempt people to touch, lean against and hug: something like the therapeutic PARO Seal robot. An interactive body-animal could help someone to calm down, to fall asleep, or become aroused. My friend has a very sensitive dash line between her paralyzed hand and receptive shoulder. She finds this convenient: she can sit on the couch, tired, watching the children play on the floor, and enjoy her spouse gently caressing her upper arm with clothes on. A nice bonus feature for prostheses that operate via neural signals.

An environmental activist drew a rollator with a front panel full of herbs and attractive salads to snack on. We were wondering if something could also be grown on the surface of a prosthesis. Short tuft moss, cress, or mushrooms as a substitute for meat? Imagine a vegan athlete explaining to a doctor that he wants to amputate his brawny leg to replace it with a less energy-hungry and more environment-friendly shiitake log plantation. Could we reduce our carbon footprint and compensate for overpopulation by harnessing our bodies for food production in the future? Literally enhance assistive technology to fight malnutrition, which is one of the major causes of disability.

I've been thinking about whether rollators could be topiary art, could consist of trees and shrubs growing to a desired shape from flower pots attached to the wheels. What had been the pariahs of assistive equipment would become desirable walking aids for tree-huggers and everyone who thinks green. The visual appearance of the walker would follow the seasons. If it was no longer needed, it could be planted in the garden. As an offshoot of this idea, I've grown organic wheelchair seedlings since 2015; I've planted them in parks, both in Finland and abroad. I predict that the updated versions of historical wooden legs will return to prosthetic fashion in the West for environmental reasons. Maybe even in living form.

Perhaps there are already prosthetic teeth on the market that taste like chocolate when they touch the tongue. When we played "the floor is lava" with the kids, I came up with a "lava lamp prosthetic" bubbling fluid and oil. A fire-proof prosthesis would guarantee sweeping victory in 
that game, help trampling down campfires, and save people from burning houses. Hydrofoil prosthesis could make it possible to walk on water. I have sketched an invisible prosthesis based on compressed air, and steps that rest on flushed air columns from the stump. A Mary Poppins umbrella-cane with a drone would fly me over level differences, and take people with visual impairments to their destinations, travelling through the air without colliding with objects.

Inspired by the leech nightmare, I've been thinking about a fishing rod prosthesis: you thread the worm through a hook on the big toe, and enjoy the Scandinavian midnight sun by the lake. In the sad version, the prosthesis of a person sitting on the pier looks like a block of stone. And an animal prosthesis, with giraffe horns at the heel, the muzzle at the metatarsus, and the giraffe neck as a telescopic pylon that lifts someone up to pick fruit from higher branches. A prosthesis that imitates a goat leg with a cloven hoof might amuse Narnia fans; an artificial foot pole could please drum mat musicians-or people with restless legs. And how about a brooch on the face instead of prosthetic eye, or a tiny sculpture for a nose?

The common denominator of all the previous examples is that they have nothing to do with practicality, or "what is good for us", because I am allergic to the structures of power. Some of us love devices that carp about mealtimes, medicine and sufficient sleep. But I don't want a tooth implant to count calories, or a crutch with a pedometer. Being born with a disability does not make me anyone's rehabilitation project. A healthy lifestyle isn't enough to satisfy my passions and goals in life. When I heard about a sweater by Ying Gao, which has metal fibres that react to the voice, I began to hope for a jacket for short statured people, with hairs that bristle if you use baby talk.

We have developed pill dispensers that tattle to the doctor if a patient does not take his medication, but we don't have necklaces that send emergency messages to politicians and the media if a home care client has not been taken out for a week. Pressure sensors and smart skincare materials sound great in prosthesis, but what if they start to read body signals and send warnings that your life is going in circles? Or even worse, that you are idling? Every year a new fashion design student wants to make an "easy-to-dress" line for wheelchair users. It's an important aim for firefighters, but people with disabilities aren't outside the fast-moving trends of fashion. The need to follow fashion applies to prostheses too, and therefore their appearance should be easy to modify. Independence is an important value, but if it reduces the clothing choices of people with disabilities from millions to a few dozen in this appearance-oriented world, it becomes one more limitation involved in living with impairments. In particular, girls and women with disabilities should receive enough personal assistance to help them into the dresses and skinny jeans that they really want. According to studies, strengthening of self-expression protects us from violence and abuse.

\section{Well-fitting prosthesis rubbing the mind}

My mother tried to find a peer group where Grandma could deal with her amputations. There were other residents with missing limbs in the nursing home, but the only discussion group was for women who had undergone mastectomy. Grandma figured that losing her ability to walk affected her femininity more than a breast removal would have. Because the stumps did not heal enough to allow for prostheses, Grandma relieved her anxiety by paying excessive attention to her clothing. My mom searched for, borrowed, and repaired outfits that Grandma demanded to get, but most of them ended up in a closet. She couldn't imagine going shopping in a wheelchair-not because of missing legs, but missing shoes!

Assistive technology invented in art workshops is often related to identity and self-expression. It is hoped that these devices can convey hints about interests and socially prestigious positions: I'm not a patient, but a parent, activist, athlete, blogger, dog trainer, culinarist, and magician. Many of the obstacles that threaten the dreams and achievements of PWDs would be removed 
if we were seen as potential co-workers, friends, spouses and loved ones, rather than being "lifted up" to walk in an upright position. Assistive devices and prosthesis are an underutilised advertising platform. Unfortunately, they often simply make people think of illnesses. In the US, I've never been asked why I'm walking with a crutch, or what's wrong with me. In Finland, this repeated curiosity about "what happened" has made me wonder how people would react if a car crash survivor wore a prosthesis made from smashed toy cars? How would curious people react to a prosthesis that looks like a dropped axe, or made to resemble a cigarette?

On Instagram, a little girl shakes an irritating stone from her shoe, even though she has a foot prosthesis. When I was introducing the "Aid of your dreams" competition to assistive engineering students, their teacher said that he had never thought that a wheelchair or walker should bring pride or emotional pleasure to its user. Even though they are kept close to the body, almost all day long. It's no secret that a corset is beautiful but a back brace is not. Why, in Finland, are prosthetic socks only available in black, white and beige, but not orange? Assistive technology that is given as medical rehabilitation doesn't transform into part of our expressive attire because we don't insist that it should.

For some, an amputated limb is a more private body part than those underneath the swimsuit. In women-only workshops, opinions are divided on whether a prosthesis should be stunningly gorgeous, or should hide the "problem areas". Brutally speaking, is a woman with a disability a "real woman" when the prosthesis gathers admiring looks, or does a person with a disability (often considered genderless) qualify as woman only when the impairments are carefully disguised? For some, a realistic cosmesis is an essential protection against uncomfortable staring, while others find silicone skin with wrinkles, blood vessels and moles more suitable for Halloween.

In 2008, the Norwegian artist Morten Traavik organised the world's first Miss Landmine competition in Angola, to provoke discussion on the use of landmines. His other goal was to empower injured women by taking beautiful pictures. Although the first prize (a prosthesis) was handed out by Angola's First Lady, Ana Paula dos Santos, some local people and Angolan organisations alleged that the project was racist, and claimed that photographing limbless women was abuse. The following year, an attempt was made to ban the competition in Cambodia, because a local ministry suddenly wanted to protect the honour and dignity of landmine victims. Traavik was a white man without disability who came from far away. Or was it just that the two taboos, women with disabilities and landmines, was too hot a combination for international attention?

\section{New interpretations of the limbs}

I wish that the first visit to the prosthetic unit after amputation would be more like the experience of looking for a new car than getting a car repaired. The customer could gasp with delight, as though watching puppies or new-born babies. They could participate in prosthesis tasting, before promising to stay together in sickness and in health.

I have been asked to give assistive device decoration workshops. My reason for refusing is that decoration is strongly related to credibility and power. Breath-taking assistive artworks such as A. Laura Brody's Le Flaneur Rollator, or Greg Hurley's Steampunk Electric wheelchair, are results of countless stages and months of work by talented professional artists. Stickers, glitter, fabrics, paint or knitwear that get added during a workshop do not necessarily decrease suspicious attitudes towards assistive equipment. Children decorate phone covers and bikes, but few adults customise their shoes and winter jackets themselves. People with disabilities are often thought to be childish. It's unfair to assume that we should be able to pimp up our mobility aids and prostheses to be street credible.

Grandma's shadow changed radically during my childhood. After her both legs were amputated at knee height, we spoke again about the prosthesis. Grandma laughed and said that she would like to get ones with nails that grow fast, like witches. A 
pedicure school did practical training at the nursing home, and Grandma entertained herself inviting new students to cut her toenails. My shrinking Grandma imagined being stronger (or dealt with the trauma) through fooling around with non-existent toes.

My prosthesis-envy, transmitted in Bosnia, got worse when images of the Alternative Limb Project spread on social media after the exhibition at the Victoria \& Albert Museum in 2013. I don't admit to having BID, a rare condition in which there is a mismatch between the mental body image and the physical body, characterised by a desire for amputation of a limb, or to become blind or deaf. Rather, it was about my interest in wearable art and statement wear. Then, in 2014, when I was browsing vintage postcards of people with parasitic limbs (a medical condition where a partly developed twin exists inside another person), I came up with a way to use prosthesis without first losing body parts.

I made the first pair of parasitic leg prostheses for a conference in Bergen in 2015. These looked like legs that branch from two to four down from the knees. The impression is somewhat similar to the multiple hands of Indian goddesses, or to Scylla's dog heads in the Odyssey. The only purpose of parasitic prostheses was to make me able to wear very high heels, but I also imagined how robotic versions would make me dance. As if by chance, on the first day of the event there was much talk about how the idea of restoring something missing is old-fashioned in a time when perceptions of the body are expanding rapidly.

We are already giving up the assumption that the number of human limbs is unconditional. New technological lumps are popping up from our hands and heads. In the children's book, Babar the elephant lifts a teacup charmingly with his trunk. My friend dreams of a tail that enables her to pull her kids closer in the street when her hands are full of grocery bags, or to lift stuff from high shelves. My son would like to have four arms and legs like da Vinci's Vitruvian man, as seen on our toilet seat cover. If the weight of the body gets redistributed in the future from two limbs onto four or even more, walking becomes softer and more swinging. The classic image in which a monkey transforms from picture to picture into a human in standing position will acquire a new evolutionary stage-a rocking human.

I predict that it is only a matter of time until parasitic prostheses become fashion. Who would not want to browse social media with parasitic hands while cooking, or to be able to both knit and bite one's nails while watching a horror movie? Pet three, four, five cats at the same time? This increase in limbs will affect the fashion industry, since we need clothes with more sleeves and legs, as well as single, un-paired shoes and gloves. Dani Clode already has a "third thumb" project, where the thumb acquires another, 3D printed, pair below the little finger on the side of the palm.

\section{In Memory}

I think of Grandma when I see wedding cars with shoes hanging behind them. In the last few weeks of her life, both of Grandma's legs were amputated just below the pelvis. The outline of the bulge under the blanket was so short that her hands extended beyond the body. She lay shivering in a hospital bed and called herself a snowman without legs. When Grandma died, I didn't dare to ask where her leg pieces had been buried over the years. Later I heard about an old belief that a person also lacks limbs in the afterlife if the amputated parts are not buried with them. And again I wondered, where in the world could those pieces have been preserved for years, in the old days?

Grandma's coffin was adult-sized, even though she could have fitted into something smaller. Years later, I read about a man who wanted to be buried as a whole, with all four of his prostheses. Perhaps they will delight archaeologists one day, since disability and assistive technology are underrepresented in historical collections. Spare parts add challenges to burial. Metal plates and implants are already popping and exploding in cremation. Soon, more and more 3D-printed tissues will be melting in the oven, or 
needing thousands of years to decompose. In that sense it may become necessary to include recycling policies in discussions about the last journey.

I haven't lost a body part. I don't know how it feels when a part of you is lost, resigns, is stolen, or dies. There are narratives about life-long crises, and grief that resembles the loss of a loved one, as well as about people who find themselves again after the shock; those for whom the prosthesis is like a springboard to new levels of cognition. Because my network consists of many people with rare diseases, I probably know more people born without, so to speak, "typical" body parts than amputated ones. People about whom it would be strange to say that they are missing something.

Some of my friends use prostheses; some don't, because of difficulties or discomfort. They say that they don't want to limit partying because of a swollen leg the morning after a heavy dinner. Or, they don't want to spend time adjusting the fit, to tolerate pressure and sweating, to take extra care of skin when wheelchairs and crutches keep them going fast. For one friend, the skin sensations in the stump are so important for functionality that everyday tasks feel clumsy with the prosthesis. And yet despite everyone's right to choose, rehabilitation guidelines for children with dysmelia, for example, contain some slightly coercive phrasing about how to make a child get used to the prosthesis.

If the definition of prosthesis is "an artificial device to replace or augment a missing or impaired part of the body", it is impossible to design a prosthesis for a person who does not feel defective, but instead feels like a manifestation of biodiversity. Pathologising some deficiencies in people, often just to justify unequal treatment, maintains discrimination. Rehabilitation should rethink the concept of assistive devices from the point of view that some people with disabilities want to act in their own refined way, some are interested in devices to improve their birth body, and only some are content with traditional compensation.

\section{Will a prosthesis have conscience, moral sense?}

When the stories about E-NABLE's free 3D printable prostheses spread in the media, I was so delighted I could have cried. I had long been afraid that high-tech devices, robots, and body-powered prostheses would remain out of reach for people with disabilities, that they would become a luxury for people without impairment. Millionaires would jog in exoskeletons that relieve the load on joints, have robots to take care of cooking, climb cliffs with prosthetic hands, and cruise along the beach boulevards in wearable cars. The E-NABLE network shared the design and printing instructions for a prosthetic hand online, free of charge to anyone anywhere in the world, and connected people with 3D printers with those who needed prostheses. We need more open-source activity around disability, but also ways to reach people outside the internet. Equality of opportunities allows people to really choose whether to use a prosthesis or other assistive technology.

Depiction of disability is almost always produced by physically privileged people, and based on imagination of what it would be like to live with an impairment, or to become disabled. When repeated regularly, these stereotypical fantasies also affect our definitions of ourselves. Prostheses based on multi-million-dollar research are presented together with sentimental stories that try to convince the general public that technologically-advanced societies will one day be able to get rid of disability. Bionics are praised for blurring boundaries between people with and without disabilities. We are assured that we should all have the right to escape from our disabled bodies. Amputees walk and talk in large arenas because they are easy to identify with. But I'm afraid that human rights policy will be different in the future if its only advocates are people who were born physically privileged and later lost that position, rather than if people who have never had such an identity also contribute.

Making empowering, stylish and intelligent assistive devices is human rights work. It is also anti-poverty work and equality work. But disability 
as a phenomenon does not disappear, even though we continue making new innovations. Tampering with individual features does not eliminate discrimination. People with inborn disabilities do not have sensors in their bodies that constantly monitor how we differ from other people. Anomaly and otherness are always put on us from outside, and it's important to question those labels. If we want to increase overall eudaemonia, we should find smarter ways to change attitudes and structures around the whole concept of well-being.

\section{Notes}

1 An artist/feminist term for the anger or discomfort some people feel when conversation turns to minority issues about intersectionality, patriarchy, and disability, making them avoid situations where these will come up. 